\title{
Practice of Inpatient Rehabilitation of the Takizawa Method and Motivative Exercise
}

\author{
Yoshiko Morita, MD. ${ }^{1}$, Takizawa Shigeo ${ }^{2}$ \\ ${ }^{1}$ Department of the rehabilitation Medicine, Okayama rehabilitation hospital (Japan), ${ }^{2}$ Biophilia Institute,
}

Keywords: inpatient, weak elderly, Takizawa's rehabilitation method, Motivative exercise, rehabilitation training with devices

\begin{abstract}
This presentation by the video broadcasting is a disclosure of the research record of the rehabilitation training with devices. To establish this training program, we needed to acquire much information from Mrs.Takizawa, PT who developed the Motivative training and many devices. But she had always advocated "I can treat them. Only I can do and I use 10,000 kinds of rehabilitation intervention techniques "and had the profits by herself all alone. Now we knew that the co-author analyzed the situation of the rehabilitation training by carrying out identification of multiple accounts under the same name as a single entity with 10,000 kinds of rehabilitation intervention techniques to 10000 numbers ${ }^{2}$. I mention specially that there had been the big sacrifice of the co-author who hadn't fear losing all, especially in his political possibilities, in order to obtain information disclosure.

We had already a chance to prove the effectiveness of developed walker by the co-author by the grant of the Japanese National Foundation, Association for Technical Aids in $2000^{1)}$, illustrated the revelation to Fig. 1 Raku walker. This rehabilitation training with devices was happened to project to join the prior study. Some of the devices in this training are shown here, Fig.2 Pata (ankle dorsi-plantar Flexion exercise device) and Fig.3 Quadriceps training with weights.

We summarized those to the video film from the analysis, which I will show you from now on. The scene of evaluation is shown in Fig. 4. Moreover, I display the written directive for enforcement on Fig. 5. Participation of the Commonwealth of the Northern Mariana Islands (CNMI) official who was invited to Japan in order to participate in this research became the foundation of the first international biophilia rehabilitation conference with the government of the CNMI of the next year, 2001. The author had confirmed the good effect in our qualitative analysis to walk acquisition ${ }^{2)}$. I required statistical analysis to Prof. Ushizawa, the top medical statistician. He could prove by FIM evaluation results that the adoption of training showed significantly effective results. In table 1 we realize the facts ${ }^{4}$. The significant differences were shown in gray.
\end{abstract}

Meantime my research presentation became the foundation of the patent ${ }^{3)}$.

We recognized the necessity to record what we saw actually by this rehabilitation training. And we obtained the KAKEN grant and recorded it in 2001. Then, we arranged and published as a video book from the Civil publication.

Although it is recognized as the fact which is not accepted except Japan and though very regrettable, in Japan after the Long-term Care Insurance Law enforcement in 2000, re-acquirement of walking ability meant the financial loss due to improvement. This economic loss is a large sum, 880 USD per month per person. It means a monthly decrease in income of 88000 dollars with 100 persons' facilities. Therefore re-acquirement of walking ability was not desired at all. The diffusion of our study results has not been realized until today by focusing on such a situation.

Then I expect that its diffusion of all over the world and scientific analysis of the Motivative exercise, which is a core intervention of the Takizawa's rehabilitation method will be performed by watching the training situation at the video session this time.

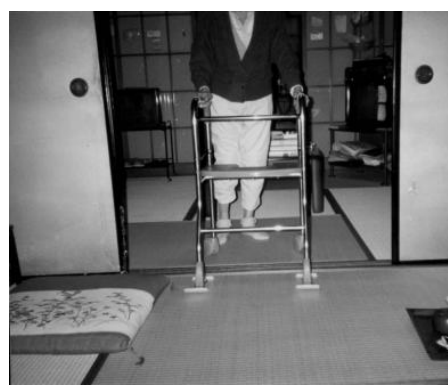

Fig. 1. Using Raku walker scenery

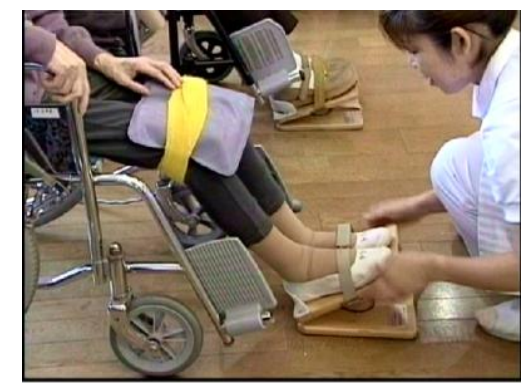

Fig. 2. Pata setting scenery

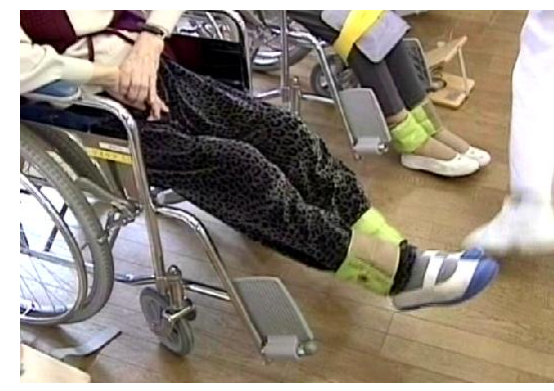

Fig. 3 Leg training with Weight 
(ankle dorsi-plantar flexion training )

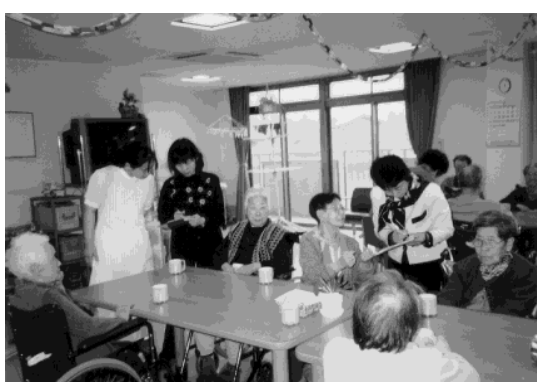

Fig. 4. Listening comprehension scenery

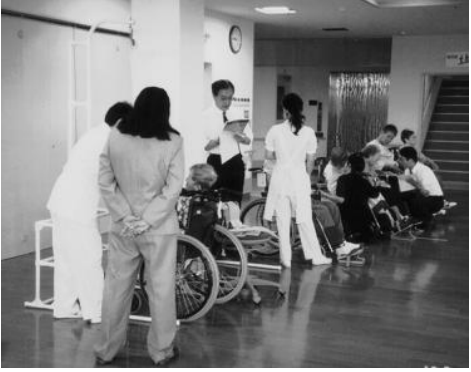

Fig. 5. Appearance of the Commonwealth of the Northern Mariana Islands official who participated

\begin{tabular}{|r|r|}
\hline Kind of motion & Momentum of motion \\
\hline $\begin{array}{r}\text { Two simple } \\
\text { Motivative Exercise } \\
\text { devices }\end{array}$ & 20 -50 Times \\
\hline $\begin{array}{r}\text { Weight band } \\
\text { Device for upper } \\
\text { extremities }\end{array}$ & $\begin{array}{r}\text { 1Kgx20 Times, } \\
\text { 20 Times }\end{array}$ \\
\hline Hot pack & $\begin{array}{r}\text { Shoulder Lt, Rt, Ancon } \\
\text { Lt, Rt, Knee Lt, Rt, } \\
\text { Ankles Lt, Rt, }\end{array}$ \\
& $\begin{array}{r}\text { Front 1,2 , back 1, } \\
\text {, Side 1,2 }\end{array}$ \\
\hline the parallel bars & Low 1,2 High 1,2 \\
\hline step & Trunk training \\
\hline gymnastics & \\
\hline
\end{tabular}

Fig. 5 Analyzed and methodized the autonomous kinetic training

Table 1. Test result of effect on improvement -all the examples

\begin{tabular}{|c|c|c|c|c|c|c|c|c|c|c|c|}
\hline \multirow[b]{2}{*}{ FIM Item } & \multicolumn{3}{|c|}{$\begin{array}{l}\text { existence of } \\
\text { improvement }\end{array}$} & \multicolumn{2}{|c|}{$\begin{array}{l}\text { the degree of } \\
\text { improvement }\end{array}$} & \multicolumn{6}{|c|}{ test } \\
\hline & - & 0 & + & mean & S.D. & $t$ & $\begin{array}{c}p \\
\text { value }\end{array}$ & Sign & $\begin{array}{c}p \\
\text { value }\end{array}$ & $\begin{array}{l}\text { Sgn } \\
\text { Rank }\end{array}$ & $\begin{array}{c}p \\
\text { value }\end{array}$ \\
\hline \multicolumn{12}{|l|}{ (self-care) } \\
\hline A. Eating & 5 & 34 & 5 & -0.07 & 0.95 & -0.48 & 0.636 & 0 & 1.000 & -2 & 0.865 \\
\hline B. Grooming & 8 & 29 & 7 & -0.41 & 1.83 & -1.48 & 0.146 & -0.5 & 1.000 & -18 & 0.317 \\
\hline C. Bathing & 9 & 21 & 14 & 0.36 & 1.78 & 1.36 & 0.182 & 0.25 & 0.405 & 50 & 0.122 \\
\hline D. Dressing - upper body & 8 & 26 & 10 & -0.05 & 1.52 & -0.20 & 0.844 & 1 & 0.815 & 3.5 & 0.881 \\
\hline E. Dressing - lower body & 8 & 26 & 10 & 0.11 & 1.78 & 0.42 & 0.674 & 1 & 0.815 & 10 & 0.674 \\
\hline F. Toileting & 4 & 28 & 12 & 0.25 & 1.75 & 0.95 & 0.350 & 4 & 0.076 & 24.5 & 0.214 \\
\hline \multicolumn{12}{|l|}{ (toilet) } \\
\hline G. Bladder management & 9 & 28 & 7 & -0.32 & 1.23 & -1.71 & 0.095 & -1 & 0.804 & -29.5 & 0.118 \\
\hline H. Bowel management & 3 & 28 & 12 & -0.16 & 1.65 & 0.65 & 0.520 & 4.5 & 0.035 & 21.5 & 0.233 \\
\hline \multicolumn{12}{|l|}{ (transfer) } \\
\hline I. Bed, chair, wheelchair & 9 & 22 & 13 & 0.34 & 1.57 & 1.44 & 0.157 & 2 & 0.525 & 38.5 & 0.204 \\
\hline J. Toilet & 9 & 24 & 11 & 0.18 & 1.57 & 0.77 & 0.448 & 1 & 0.824 & 24 & 0.378 \\
\hline K. Tub, Shower & 9 & 31 & 4 & -0.20 & 1.19 & -1.14 & 0.262 & -2.5 & 0.267 & -14.5 & 0.326 \\
\hline \multicolumn{12}{|l|}{ (move) } \\
\hline L. Walk & 2 & 27 & 15 & 0.57 & 1.68 & 2.25 & 0.030 & 6.5 & 0.002 & 48 & 0.023 \\
\hline M. Stairs & 5 & 36 & 3 & -0.16 & 0.91 & -1.16 & 0.254 & -1 & 0.727 & -7.5 & 0.375 \\
\hline \multicolumn{12}{|l|}{ (communication) } \\
\hline N. Comprehension (auditory) & 1 & 36 & 7 & 0.30 & 1.07 & 1.83 & 0.074 & 3 & 0.070 & 12.5 & 0.102 \\
\hline O. Expression (verbal) & 5 & 33 & 6 & 0.00 & 1.57 & 0.00 & 1.000 & 0.5 & 1.000 & 0 & 1.000 \\
\hline \multicolumn{12}{|l|}{ (social cognition) } \\
\hline P. Social interaction & 3 & 39 & 2 & -0.16 & 1.20 & -0.88 & 0.384 & -0.5 & 1.000 & -3 & 0.500 \\
\hline Q. Problem solving & 4 & 31 & 9 & 0.07 & 1.42 & 0.32 & 0.752 & 2.5 & 0.267 & 13 & 0.390 \\
\hline R. Memory & 5 & 29 & 10 & 0.00 & 1.22 & 0.00 & 1.000 & 2.5 & 0.302 & 4.5 & 0.829 \\
\hline FIM total & 16 & 5 & 22 & 0.88 & 12.83 & 0.45 & 0.654 & 3 & 0.418 & 58 & 0.407 \\
\hline
\end{tabular}

Reference

1) Yoshiko Morita, Clinical Evaluation of a New Type of Walker with a Seat and Two Fore Fleds, BIOPHILIA Vol. 2015 (2015) No. 1 Memorial Edition for the Linking ISSN Registration p. 42-47 http://doi.org/10.14813/ibra.2015.42

2) Yoshiko Morita, Tetsuhiko Kimura, et.al., Enforcement on the motivative exercise by the the Takizawa method. Japanese Association of Rehabilitation Medicine, Tokyo . June 24, 2000: 413.

3) Shigeo TAKIZAWA, How to Invent the Autonomous Rehabilitation Method (Takizawa method) BIOPHILIA Vol. 2014 (2014) No. 1 BIOPHILIA p. 1-6 http://doi.org/10.14813/ibra.2014.1

4) Kenji Ushizawa, Shigeo Takizawa,et al, Statistical Evaluation of Rehabilitation to the Disabled Elderly Based on the Takizawa Method、BIOPHILIA Vol. 2015 (2015) No. 1 Memorial Edition for the Linking ISSN Registration p. 19-27 http://doi.org/10.14813/ibra.2015.19 